\section{Biological agents for giant cell arteritis: treat to target}

In a case series published in the Annals of the Rheumatic Diseases, Conway et $a l^{1}$ reported a significant steroid-sparing effect of ustekinumab (monoclonal antibody to interleukin (IL)-12 and IL-23) in 14 patients with giant cell arteritis (GCA). Recently, Ferfar et $a l^{2}$ summarised current evidence showing the efficacy of tocilizumab and abatacept in patients with GCA. In the ongoing multicentre, randomised GiACTA trial (NCT01791153), the efficacy and safety of tocilizumab will be evaluated in approximately 250 patients with active GCA. Another randomised, placebocontrolled trial (NCT02531633) aims to study sirukumab (a fully human anti-IL-6 immunoglobulin G1א) in approximately 204 subjects with a diagnosis of GCA. Therefore, in the nearest future we will probably face a wider use of biological agents as a secondline treatment for relapsing GCA and maybe as a first line in patients with more unfavourable prognosis. Should we welcome biologics in the current framework of treatment? On the one hand, the steroid-sparing effect of these medications is particularly valuable for the elderly patients with GCA who usually develop adverse events related to glucocorticoids and frequently relapse during tapering the dose of prednisone. Furthermore, it is expected that certain biological agents may have antiatherosclerotic effect that is currently under investigation in the randomised controlled trials (eg, the Canakinumab Antiinflammatory Thrombosis Outcomes Study (NCT01327846) that will evaluate canakinumab in 17200 patients with coronary artery disease and persistently elevated $\mathrm{C}$ reactive protein). On the other hand, glucocorticoids are cheap and effective in a significant proportion of patients while the safety of biological agents should not be overestimated and their efficacy requires confirmation in further studies. Therefore, the possible indications for biological treatment should be defined in patients with GCA. The concept of treat to target is popular in the modern rheumatology, including systemic vasculitides. ${ }^{3}$ What we expect from therapy for GCA and what are the possible targets for treatment?

\section{SYMPTOMS RELIEF AND INDUCTION OF REMISSION}

Glucocorticoids rapidly (within few days) improve headache and other signs and symptoms in the majority of patients with newly diagnosed GCA. More aggressive treatment is of value in patients with ophthalmic involvement and aortoarteritis. Conway et al reported complete or partial improvement of arteries wall thickening on repeated CT angiography after treatment with ustekinumab in all five patients with large vessel vasculitis. These data are promising but should be confirmed in further studies, particularly in patients with visual impairment.

\section{PREVENTION AND TREATIMENT OF RELAPSES}

Currently, relapsing GCA is one of the main indications for the off-label administration of biological agents though criteria of relapse or recurrence are poorly defined. The isolated increase in inflammatory biomarkers is usually not sufficient to diagnose a relapse $^{4}$ while clinical scores, such as the Birmingham Vasculitis Activity Score (BVAS), have only limited utility in GCA. ${ }^{5}$ ${ }^{18}$ Fluorodeoxyglucose positron-emission tomography is a promising method though its value for evaluation of GCA activity is not established. ${ }^{6}$ In the Conway et al study, persistent constitutional symptoms and elevated acute-phase reactants initially felt to be possibly related to active GCA were ultimately attributed to an alternative cause in two of five patients. Therefore, a proportion of patients with GCA may be overtreated, given the difficulties in establishing relapse of vasculitis.

\section{PREVENTION OF ISCHAEMIC COMPLICATIONS}

In the large-scale datalink study (5827 patients with GCA and 37090 controls), Robson et $a l^{7}$ showed that patients with GCA were at increased risk of cardiovascular and cerebrovascular disease but predictors of ischaemic events were non-specific and identical in the GCA and non-GCA cohorts (eg, age $>80$ years and male gender). Of note, other authors did not confirm that association. ${ }^{8}$ Ischaemic complications (except visual loss) are related to atherosclerosis in the majority of patients with GCA. The risk of cardiovascular and cerebrovascular events may be probably diminished by low-dose aspirin, statins and aggressive modification of traditional risk factors while the benefit of current anti-inflammatory treatment is likely modest if any, for example, results of integrated analysis of data from phase II/III clinical studies suggested neither increased nor diminished risk of myocardial infarction or stroke in ustekinumab-treated patients with psoriasis compared with the general US and psoriasis populations. ${ }^{9}$

\section{IMPROVED SURVIVAL}

Unlike ANCA-associated vasculitis, ${ }^{10}$ early and late mortality in patients with GCA is comparable to that in the general population or increased only slightly. ${ }^{11}$ In our own cohort of 115 patients with GCA (average age of 66.6 years), 5-year and 10-year survival calculated by Kaplan-Meier method was $97.1 \%$ and $95.0 \%$, respectively (figure 1). Moreover, the average Vasculitis Damage Index at 1 year was only 2.4. Therefore, it is important not to worsen this favourable prognosis by more intensive immunosuppression that can predispose patients to life-threatening complications, for example, infections. Of note, a multicentre, longitudinal, disease-based registry Psoriasis Longitudinal Assessment and Registry in 11466 patients with psoriasis showed that treatment with ustekinumab, unlike adalimumab or infliximab, was not associated with increased risk of serious infections compared with non-methotrexate and nonbiological therapies. ${ }^{12}$ These data are reassuring for the elderly patients with GCA who are particularly prone to infectious

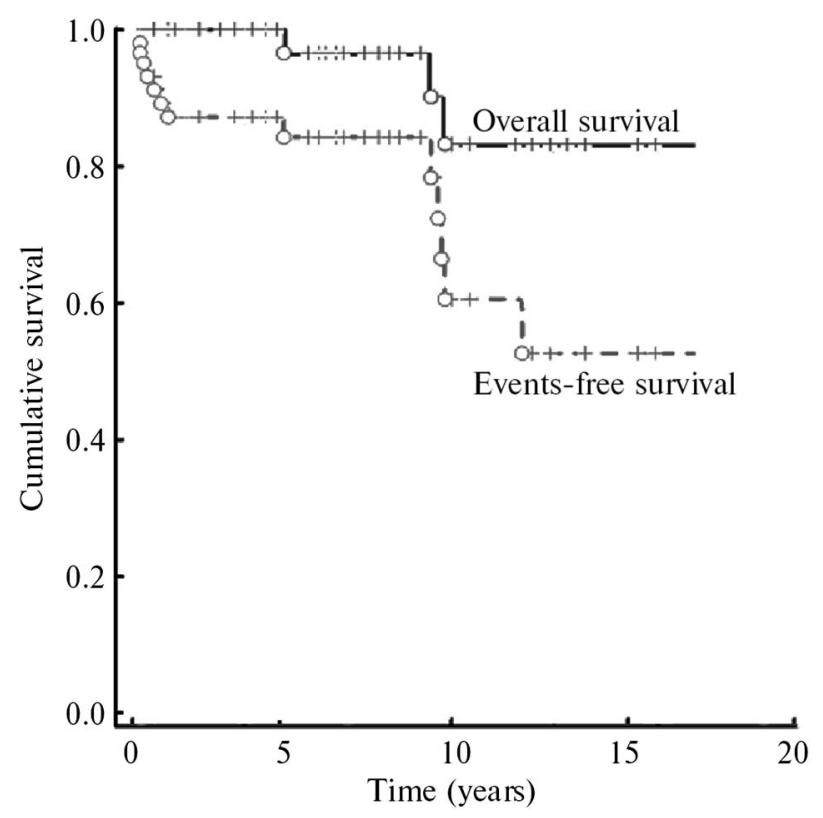

Figure 1 Kaplan-Meier curves for overall and event-free survival in a cohort of 115 patients with giant cell arteritis. 'Events' included visual loss, myocardial infarction, stroke and transitory ischaemic attacks. 
complications though the limitations of registry-based analysis should be borne in mind.

\section{PATIENT-REPORTED OUTCOMES}

Patients with GCA and physicians may have different ratings of the impact of vasculitis. Therefore, patient preferences/perspectives should be incorporated into GCA assessment. In one study, the Medical Outcomes Study Short-Form 36 scores did not correlate with the presence of vision loss at baseline, systemic complications or side effects of steroid therapy ${ }^{13}$ while diseasespecific instruments for GCA are currently unavailable. Moreover, we will probably need age-specific questionnaires to improve validity of outcomes measure in the elderly patients with GCA. Particular issues in the assessment of health-related quality of life (QOL) in the older patient populations include a poor relationship between QOL and disability/disease severity, the dynamic nature of QOL, comorbidity and generally impaired physical function that may discriminate older persons. ${ }^{14}$

There is another potential issue faced in interpreting clinical evidence. Published clinical studies usually recruited patients with biopsy-proven GCA, while in real life in a significant proportion of patients GCA will be diagnosed and treated without temporal artery biopsy (TAB). Some authors even suggest that $\mathrm{TAB}$ does not affect management in the majority of patients with suspected GCA and may be beneficial only for patients who score 2 or 3 on the American College of Rheumatology criteria for GCA without biopsy. ${ }^{15}$ Negative TAB does not exclude GCA. Furthermore, biopsy-negative and biopsy-proven GCA may have a different clinical spectrum. Gonzalez-Gay et $a l^{16}$ showed in a retrospective study that biopsy-negative patients usually presented with headache and polymyalgia rheumatica but had less severe ischaemic complications compared with that in biopsyproven GCA. It is tempting to speculate that the data from clinical trials are not fully representative of the real world and may overestimate the unmet needs in the treatment of GCA.

In summary, a list of promising biological agents that may be beneficial in patients with GCA is expanding and currently includes tocilizumab, abatacept, sirukumab and ustekinumab. A natural history of GCA is not completely understood, but in general it has a relatively favourable prognosis and usually does not cause significant irreversible damage. Actually, in a proportion of patients drug-induced damage may be even more important. Therefore, overtreatment should be avoided in patients with GCA, and the possible targets for biological therapy should be well defined. While awaiting additional evidence, these agents are well suited only for selected patients with recurrent/relapsing course of GCA or predefined unfavourable prognostic factors.

\section{Sergey Moiseev, ${ }^{1}$ Pavel Novikov, ${ }^{1}$ Alexey Meshkov, ${ }^{1}$ Ilya Smitienko ${ }^{2}$ \\ ${ }^{1}$ Clinic of Nephrology, Internal and Occupational Diseases, Sechenov First Moscow State Medical University, Moscow, Russia \\ ${ }^{2}$ Russian University of Peoples' Friendship, Moscow, Russia}

Correspondence to Professor Sergey Moiseev, Clinic of Nephrology, Internal and Occupational Diseases, Sechenov First Moscow State Medical University, Rossolimo, 11/5, Moscow 119435, Russia; clinpharm@mtu-net.ru
Competing interests None declared.

Provenance and peer review Not commissioned; internally peer reviewed.

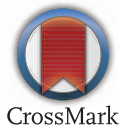

To cite Moiseev S, Novikov P, Meshkov A, et al. Ann Rheum Dis 2016;75:e58

Received 14 June 2016

Accepted 19 June 2016

Published Online First 8 July 2016

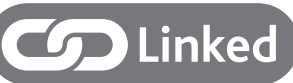

- http://dx.doi.org/10.1136/annrheumdis-2016-210082

Ann Rheum Dis 2016;75:e58. doi:10.1136/annrheumdis-2016-210061

\section{REFERENCES}

1 Conway R, O'Neill L, O'Flynn E, et al. Ustekinumab for the treatment of refractory giant cell arteritis. Ann Rheum Dis 2016;75:1578-9.

2 Ferfar Y, Mirault T, Desbois AC, et al. Biotherapies in large vessel vasculitis. Autoimmun Rev 2016;15:544-51.

3 Luqmani RA. Treat-to-target in vasculitis: is this a sensible approach? Clin Exp Rheumatol 2012;30(Suppl 73):S149-53.

4 Bienvenu B, Ly KH, Lambert M, et al. Management of giant cell arteritis: Recommendations of the French Study Group for Large Vessel Vasculitis (GEFA). Rev Med Interne 2016;37:154-65.

5 Kermani TA, Cuthbertson D, Carette $S$, et al. The Birmingham Vasculitis Activity Score as a measure of disease activity in patients with giant cell arteritis. J Rheumatol 2016;43:1078-84

6 Novikov PI, Meshkov AD, Moiseev SV. Positron emission tomography in giant cell arteritis: a new diagnostic tool? Ann Rheum Dis 2014;73:e70.

7 Robson JC, Kiran A, Maskell J, et al. Which patients with giant cell arteritis will develop cardiovascular or cerebrovascular disease? A clinical practice research datalink study. J Rheumatol 2016;43:1085-92.

8 Ungprasert $\mathrm{P}$, Koster MJ, Warrington KJ. Coronary artery disease in giant cell arteritis: a systematic review and meta-analysis. Semin Arthritis Rheum 2015;44:586-91.

9 Reich K, Langley RG, Lebwohl M, et al. Cardiovascular safety of ustekinumab in patients with moderate to severe psoriasis: results of integrated analyses of data from phase II and III clinical studies. Br J Dermatol 2011;164:862-72.

10 Novikov PI, Moiseev SV, Kuznetsova El, et al. Changing patterns of clinical severity and risk of mortality in granulomatosis with polyangiitis over four decades: the Russian experience. Rheumatol Int 2015:35:891-8.

11 Baslund B, Helleberg M, Faurschou M, et al. Mortality in patients with giant cell arteritis. Rheumatology (Oxford) 2015;54:139-43.

12 Kalb RE, Fiorentino DF, Lebwohl MG, et al. Risk of serious infection with biologic and systemic treatment of psoriasis: results from the Psoriasis Longitudinal Assessment and Registry (PSOLAR). JAMA Dermatol 2015;151: 961-9.

13 Kupersmith MJ, Speira R, Langer $R$, et al. Visual function and quality of life among patients with giant cell (temporal) arteritis. J Neuroophthalmol 2001;21: 266-73.

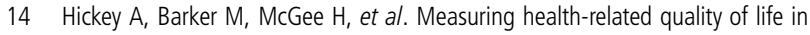
older patient populations: a review of current approaches. Pharmacoeconomics 2005:23:971-93.

15 Quinn EM, Kearney DE, Kelly J, et al. Temporal artery biopsy is not required in all cases of suspected giant cell arteritis. Ann Vasc Surg 2012;26:649-54.

16 Gonzalez-Gay MA, Garcia-Porrua C, Llorca J, et al. Biopsy-negative giant cell arteritis: clinical spectrum and predictive factors for positive temporal artery biopsy. Semin Arthritis Rheum 2001;30:249-56. 